\title{
Numerical simulation of the marine boundary layer characteristics over the Bay of Bengal as revealed by BOBMEX-98 Pilot experiment
}

\author{
A N V Satyanarayana ${ }^{1}$, U C Mohanty ${ }^{1}, \mathrm{~N} \mathrm{~V} \mathrm{SAM}^{1}$, Swati BAsu ${ }^{2}$ and V N Lykossov ${ }^{3}$ \\ ${ }^{1}$ Centre for Atmospheric Sciences, Indian Institute of Technology Delhi, New Delhi, India \\ ${ }^{2}$ National Centre for Medium Range Weather Forecasting, New Delhi, India \\ ${ }^{3}$ Institute of Numerical Mathematics, Moscow, Russia
}

\begin{abstract}
An attempt has been made to study the marine boundary layer characteristics over Bay of Bengal using BOBMEX (Bay of Bengal and Monsoon Experiment) pilot experiment data sets, which was conducted between 23rd October and 12th November 1998 on board ORV Sagar Kanya. A one-dimensional multilevel atmospheric boundary layer with TKE- $\varepsilon$ closure scheme is employed to study the marine boundary layer characteristics. In this study two synoptic situations are chosen: one represents an active convection case and the other a suppressed convection. In the present article the marine boundary layer characteristics such as temporal evolution of turbulent kinetic energy, height of the boundary layer and the airsea exchange processes such as sensible and latent heat fluxes, drag coefficient for momentum are simulated during both active and suppressed convection. Marine boundary layer height is estimated from the vertical profiles of potential temperature using the stability criterion. The model simulations are compared with the available observations.
\end{abstract}

\section{Introduction}

Marine Boundary Layer (MBL) plays an important role in the atmospheric energy studies. The vertical structure of the MBL in the tropics depends on the interaction cycle of the air-sea exchange, vertical transport mechanism and the large-scale flow. The energy for driving the atmospheric disturbances is provided by the underlying ocean through sensible and latent heat fluxes and thus the ocean-atmosphere coupling takes place. It is important to study the MBL characteristics to understand the air-sea exchange processes and the transport mechanism in the context of large-scale synoptic features such as the monsoon. Very few studies have been conducted on MBL due to paucity of data. Holt and Raman (1988) have simulated the turbulent characteristics of the marine boundary layer. Satyanarayana et al (1999) studied some aspects of MBL over the Indian Ocean using
INDOEX Cruise \#120 data sets. A pilot experiment acronym as BOBMEX (Bay of Bengal and Monsoon Experiment) was conducted on board ORV Sagar Kanya during 23rd October to 12th November 1998 to understand the air-sea interaction processes and marine boundary layer characteristics over the Bay of Bengal. The main aim of the present study is to understand the marine boundary layer characteristics in different synoptic situations that are observed during the pilot experimental phase. In the present article the MBL characteristics such as temporal evolution of turbulent kinetic energy (TKE), MBL height and surface layer parameters such as sensible and latent heat fluxes, drag coefficient are simulated during active and suppressed convective conditions. The model has also generated the vertical profiles of zonal and meridional wind components, potential temperature and specific humidity. The simulated MBL features are compared with available observations.

Keywords. BOBMEX; Turbulent Kinetic Energy; Marine Boundary Layer; flux. 


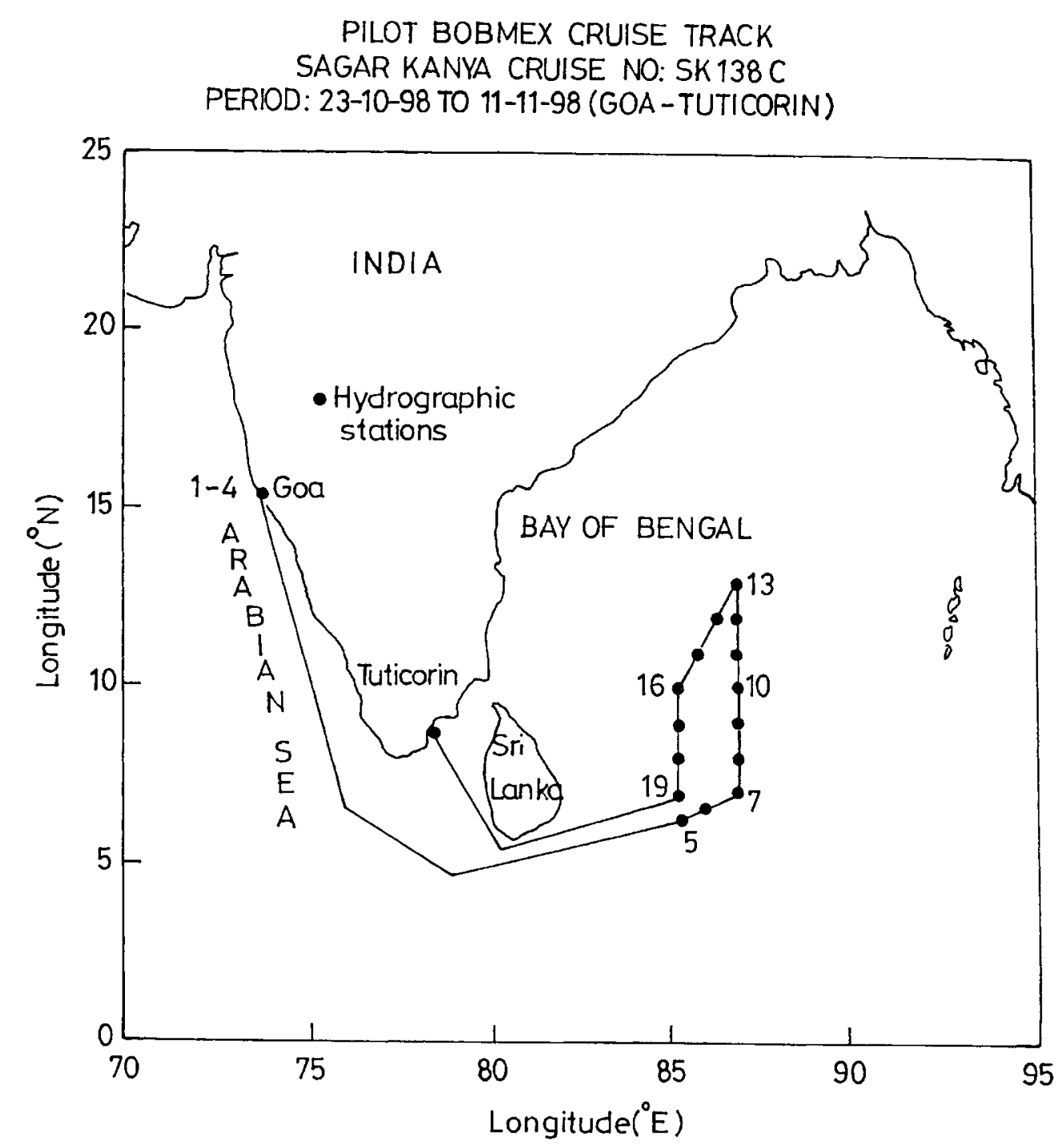

Figure 1. Cruise track of ORV Sagar Kanya during BOBMEX-98 pilot experiment.

\section{Data}

The BOBMEX-Pilot experiment was carried out on board ORV Sagar Kanya. The ship left Mormugao on 23rd October 1998, moving parallel to the West Coast up to $5^{\circ} \mathrm{N}$ and then turned towards the Bay of Bengal. The first time series observation station $\left(7^{\circ} \mathrm{N}, 87^{\circ} \mathrm{E}\right)$ was on 30th October where the ship was stationed for two days, and then it moved towards north $\left(10^{\circ} \mathrm{N}\right.$, $\left.87^{\circ} \mathrm{E}\right)$ to the second stationary position for two days (2nd - 3rd November). The ship reached the last stationary observation point $\left(13^{\circ} \mathrm{N}, 7^{\circ} \mathrm{E}\right)$ on 5 th November and was positioned there for that day. The ship sailed back on 6th November and reached Tuticorin on 12th November 1998. The track of the BOBMEX pilot experiment is shown in figure 1.

During the experimental phase an active convective activity was observed from 31st October to 2nd November 1998 while during 3rd - 5th November 1998 no significant weather activity was noticed as verified from satellite pictures (Kalsi 1999) and on board surface synoptic observations (not presented). In this study, these two distinctly different synoptic scenarios representing active and suppressed convection are considered.

Vertical profiles of temperature and moisture at different pressure levels, observed by launching radiosonde, low-level sonde and mini-sonde on board ORV Sagar Kanya, are used for the study. The surface synoptic observations viz. sea surface temperature, wind speed, wind direction, surface pressure, air temperature and dew point temperature are also considered for the study. Due to the absence of wind profile observations, the vertical profiles of wind that are obtained from the National Centre for Medium Range Weather Forecasting (NCMRWF) operational analysis, are used in the present study. The wind profiles are extracted and interpolated in the vertical from the coarse horizontal as well as vertical resolution NCMRWF analyses during the period of the study. 
For two days i.e. 1st and 3rd November, sonic anemometer (three-dimensional fast response wind components and temperature) and Lyman-alpha (fast response humidity) observations are available and the same are used for verification of simulated fluxes by the MBL model.

\section{Methodology}

A multi-level one-dimensional model with TKE- $\varepsilon$ closure scheme is used to simulate the MBL characteristics (Mellor and Yamada 1974; Lykossov and Platov 1992). The model has 40 levels in the vertical and layer thickness of $50 \mathrm{~m}$ from the surface to $2000 \mathrm{~m}$. The model adopts TKE- $\varepsilon$ parameterisation scheme for the mixed layer, while the surface layer similarity approach is used for the constant flux layer close to the ocean surface. More details regarding the model are given in Lykossov and Platov (1992), and Satyanarayana et al (1999). The model equations are

$$
\begin{aligned}
& \frac{\partial u}{\partial t}=-\frac{\partial \overline{u^{\prime} w^{\prime}}}{\partial z}+f v+\tilde{p}_{x} / \tilde{\rho} \\
& \frac{\partial v}{\partial t}=-\frac{\partial \overline{v^{\prime} w^{\prime}}}{\partial z}-f u-\tilde{p}_{y} / \tilde{\rho}, \\
& \frac{\partial \theta}{\partial t}+u \tilde{\theta}_{x}+v \tilde{\theta}_{y}=-\frac{\partial \overline{\theta^{\prime} w^{\prime}}}{\partial z}+Q_{r}+Q_{f} \\
& \frac{\partial q}{\partial t}+u \tilde{q}_{x}+v \tilde{q}_{y}=-\frac{\partial \overline{q^{\prime} w^{\prime}}}{\partial z}+E_{p}-C \\
& \frac{\partial q_{w}}{\partial t}+u \tilde{q}_{w x}+v \tilde{q}_{w y}=-\frac{\partial \overline{q_{w}^{\prime} w^{\prime}}}{\partial z}-E_{p}+C-P \\
& \frac{\partial E}{\partial t}=\left(-\overline{u^{\prime} w^{\prime}} \frac{\partial u}{\partial z}+\overline{v^{\prime} w^{\prime}} \frac{\partial v}{\partial z}+\frac{g}{\rho} \overline{\rho^{\prime} w^{\prime}}+\varepsilon\right)-\frac{\partial \overline{w^{\prime} E^{\prime}}}{\partial z}, \\
& \frac{\partial \varepsilon}{\partial t}=-C_{1} \frac{\varepsilon}{b}\left(-\overline{u^{\prime} w^{\prime}} \frac{\partial u}{\partial z}+\overline{v^{\prime} w^{\prime}} \frac{\partial v}{\partial z}+\frac{g}{\rho} \overline{\rho^{\prime} w^{\prime}}+\varepsilon\right) \\
& \quad-\frac{\partial \overline{w^{\prime} \varepsilon^{\prime}}}{\partial z},
\end{aligned}
$$

where $u, v$, and $w$ are $x$-, $y$ - and $z$-components of the wind velocity, $\theta$ is the potential temperature, $q$ is the specific humidity, $q_{w}$ is the specific liquid-water content, $E$ is turbulent kinetic energy and $\varepsilon$ is dissipation, $\rho$ is the density of the air-water-water vapor mixture, $\left(\tilde{p}_{x} \tilde{p}_{y}\right)\left(\tilde{\theta}_{x} \tilde{\theta}_{y}\right)\left(\tilde{q}_{x} \tilde{q}_{y}\right)$ are components of horizontal gradients of the pressure, potential temperature, specific humidity and specific liquid-water content in the free atmosphere, $Q_{r}$ and $Q_{f}$ are rates of the heat change due to radiation and phase transitions of the water, $C$ and $E_{p}$ are rates of phase changes: water vapor to liquid water and water to water vapor, $P$ is the precipitation rate, $\rho \overline{u^{\prime} w^{\prime}}, \rho \overline{v^{\prime} w^{\prime}}, \rho \overline{\theta^{\prime} w^{\prime}}, \rho \overline{q^{\prime} w^{\prime}}$ and $\rho \overline{q_{w}^{\prime} w^{\prime}}$ are the vertical turbulent fluxes of momentum, heat, water vapor and liquid water, $f$ is coriolis parameter, $g$ is acceleration due to gravity, $C_{1}$ and $b$ are constants.

Marine boundary layer height is estimated from the vertical profiles of potential temperature using stability analysis for comparing the model simulations. Eddy correlation method (Stull 1988) is employed to compute the fluxes of sensible heat and latent heat using sonic anemometer and Lyman-alpha data for comparison purposes.

\section{Initial and boundary conditions}

For the model initial and boundary conditions, data comprising of vertical profiles of winds, temperature and humidity at different pressure levels are utilized. Using linear interpolation technique the data sets of vertical profiles of above cited parameters are prepared at every $50 \mathrm{~m}$ in vertical from sea level to the top of model domain. The maximum height of the turbulent boundary layer (top of the PBL) is chosen as the upper boundary. At the top of the boundary layer, the wind speeds, the potential temperature and the moisture attain the observed values at that height. The TKE and energy dissipation is assumed to vanish at that height. The top of the model domain was kept at $2000 \mathrm{~m}$. These data sets served as an input to the PBL model as well as time-varying lateral boundary conditions to study the MBL characteristics.

The boundary conditions are prepared using the surface synoptic observations such as surface pressure, sea surface temperature and surface relative humidity that are collected on board ORV Sagar Kanya.

The active convection case (from 31st October 2nd November) hereafter referred as Case-1 and the suppressed convection case (3rd - 5th November) referred as Case-2. For Case-1, the model initial conditions are prepared using the vertical profiles of zonal and meridional wind, potential temperature and specific humidity of 0530 IST on 31st October and the model is integrated for 48 hours. Similarly, the initial conditions of Case- 2 are prepared using the data of 0700 IST on 3rd November and the model is integrated for 48 hours. The hourly simulations are stored for the purpose of comparison.

\section{Results and discussion}

The model simulations consist of the vertical profiles of zonal and meridional wind components, potential temperature and specific humidity, MBL height, sensible and latent heat fluxes, drag coefficient along with the temporal variation of TKE. The simulated profiles are compared with the available observations. The observed profiles of zonal and meridional wind, potential temperature and specific humidity are linearly 
interpolated in the vertical (at every $50 \mathrm{~m}$ interval up to $2000 \mathrm{~m}$ ) and the resultant values are used.

The vertical profiles of zonal and meridional wind after 24 and 48 hours simulations along with the observations of Case- 1 and Case- 2 are presented in figures 2 and 3, respectively. The vertical profiles of potential temperature and specific humidity after 24 and 48 hours simulations along with the observations of Case- 1 and Case- 2 are depicted in figures 4 and 5, respectively. For Case-1, 24 hour and 48 hour simulation represent 1st November 1998, 0530 IST and 2nd November 1998, 0530 IST respectively. Similarly for Case-2, the 24 hour and 48 hour simulation represent 4th November 1998, 0530 IST and 5th November 1998, 0530 IST, respectively.

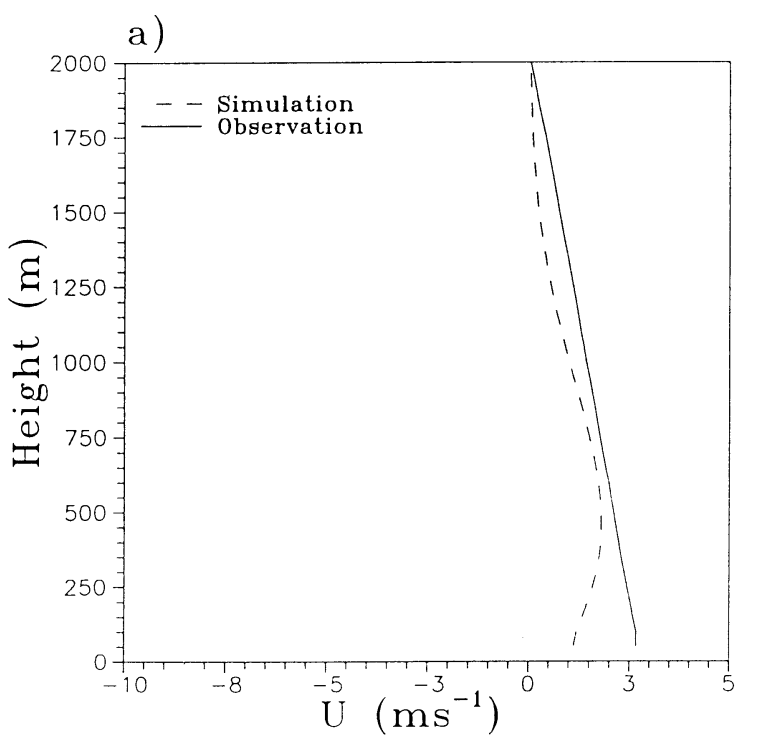

c)

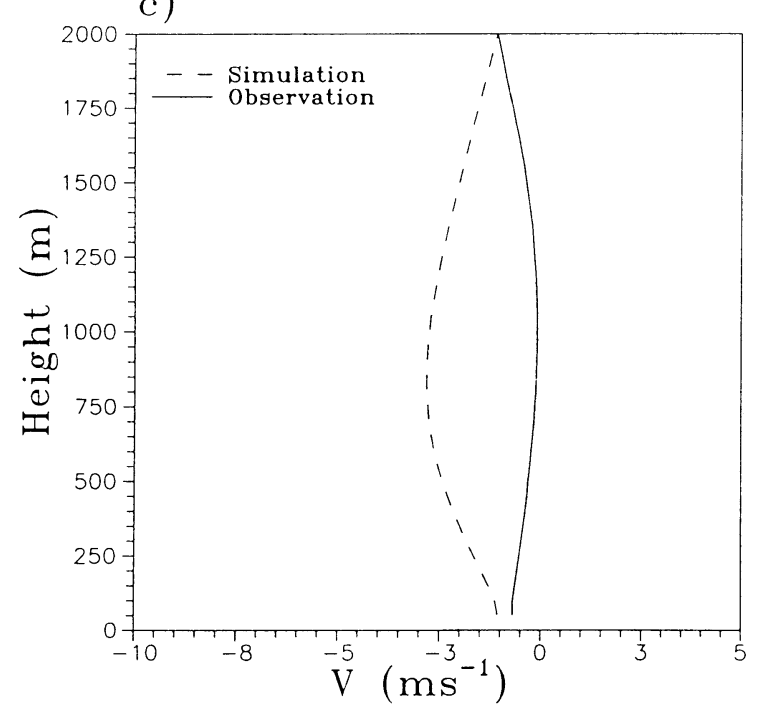

In general, the model simulations of zonal and meridional components are found to be in good agreement with the observations with some differences, as one can see in figures 2(c) and 3(c), which represent the meridional component of the wind. The model simulations of potential temperature and specific humidity are in fairly good agreement with the observations, although there are differences between the simulated and observed values, as can be seen in figures 4 and 5 .

In figure $4(\mathrm{a})$, the nature of the simulated potential temperature profile is similar to that of the observed profile except in the first $250 \mathrm{~m}$ of the layer. Neutral conditions are present in the lower layers of the simulated profile whereas stable conditions are noticed in

b)
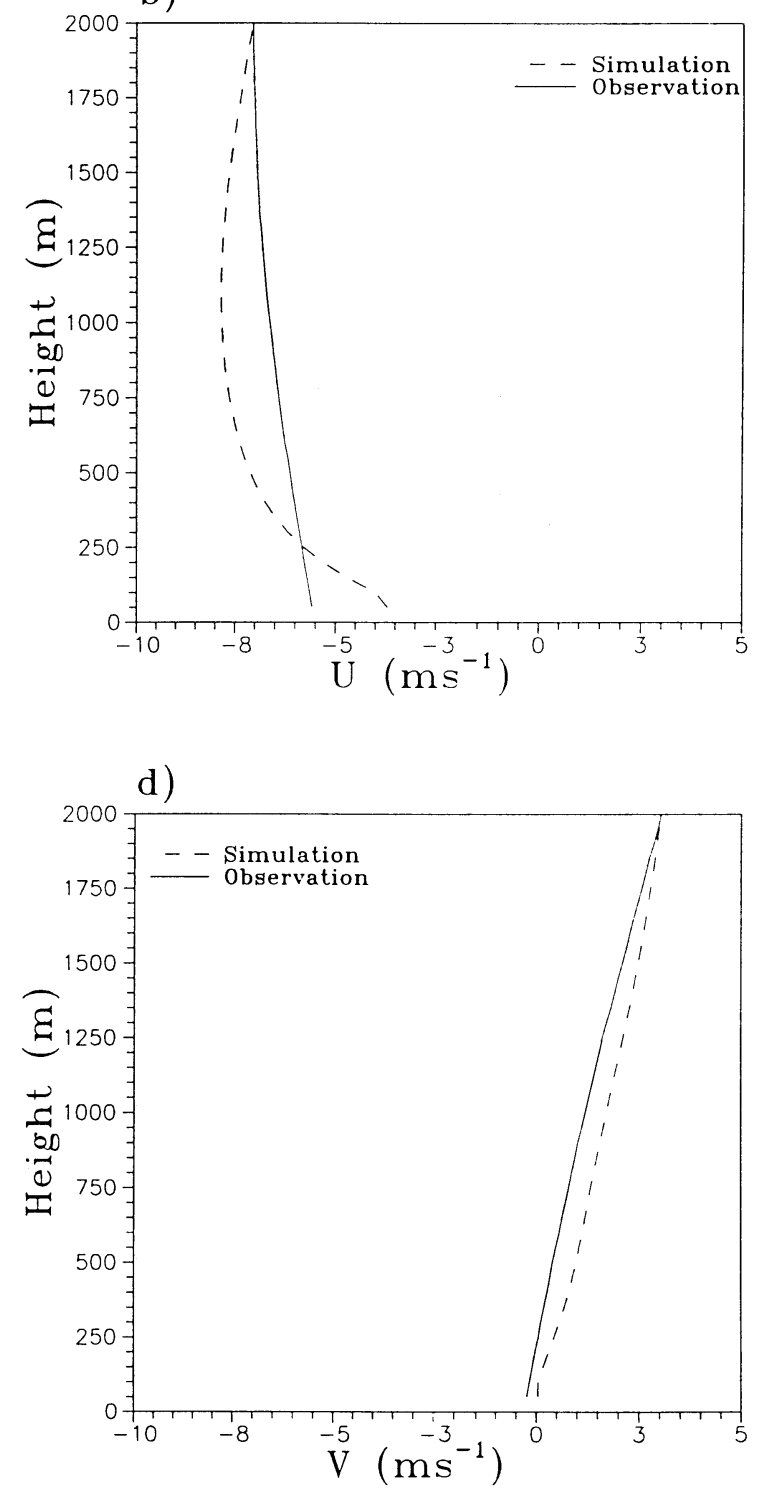

Figure 2. Vertical profiles of (a) zonal wind $\left(\mathrm{ms}^{-1}\right)$ at 00 UTC on 1st November 1998; (b) same as (a) but at 00 UTC on 2nd November 1998; (c) meridional wind $\left(\mathrm{ms}^{-1}\right.$ ) at 00 UTC on 1st November 1998 and; (d) same as (b) but at 00 UTC on 2nd November 1998 along with the observations of Case-1. 
a)

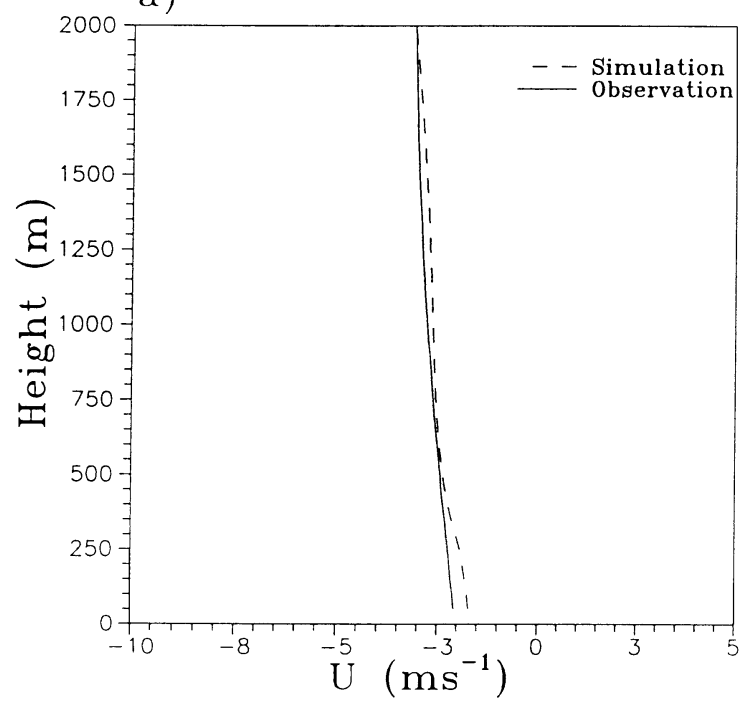

c)

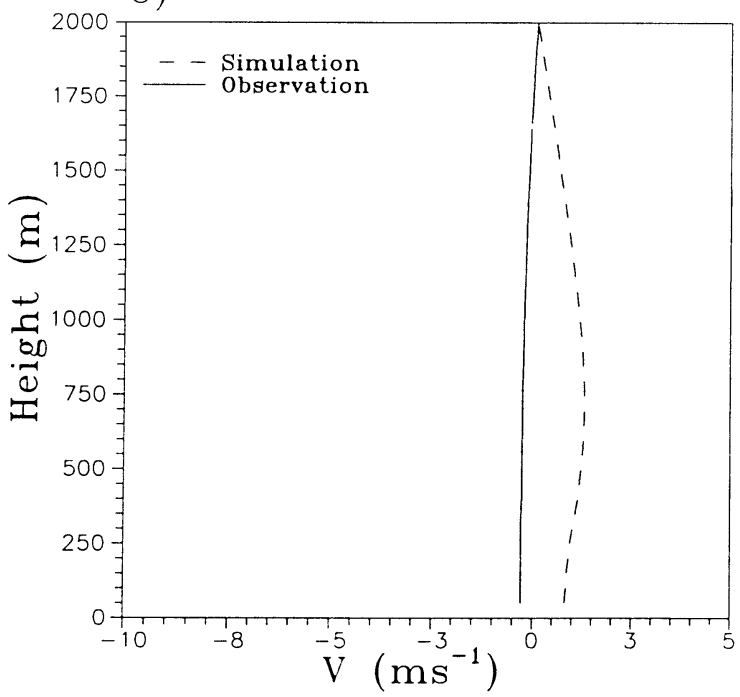

b)

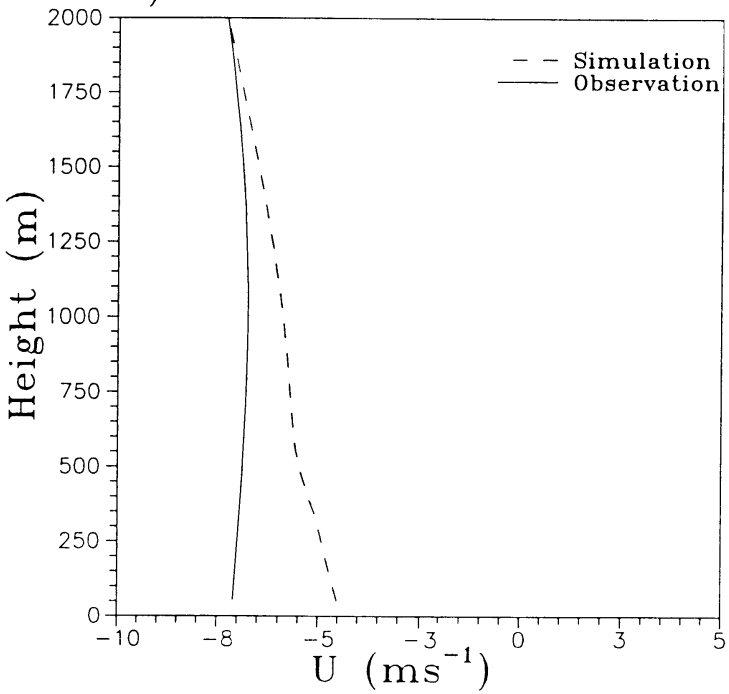

d)

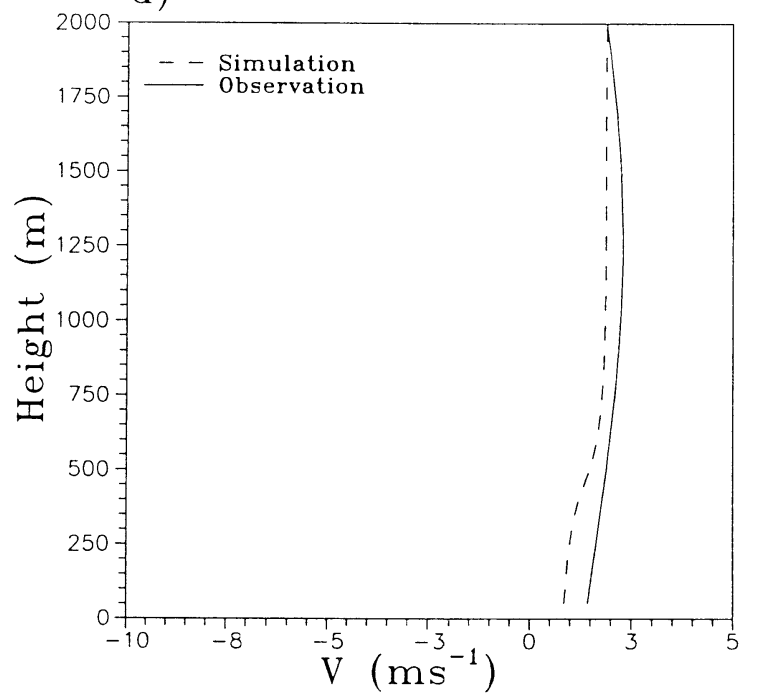

Figure 3. Vertical profiles of (a) zonal wind $\left(\mathrm{ms}^{-1}\right)$ at 00 UTC on 4th November 1998; (b) same as (a) but for 00 UTC on 5th November 1998; (c) meridional wind $\left(\mathrm{ms}^{-1}\right)$ at 00 UTC on 4th November 1998 and; (d) same as (b) but for 5th November 1998 along with the observations of Case-2.

the observations. A similar situation is noticed in figure 4(b). In figures 5(a) and 5(b), one can see the good agreement of simulated potential temperature profile with the observations. The model could simulate the neutral conditions that are noticed in the observations reasonably well. A maximum difference of $\sim 1.2 \mathrm{~K}$ is found between simulations and observations (figure $5(\mathrm{a})$ ) and it is $\sim 1.6 \mathrm{~K}$ as noticed in figure $5(\mathrm{~b})$.

The vertical variation of the simulated specific humidity is comparable with the observations as shown in figures 4(c) and 4(d). An increase of $\sim 3 \mathrm{~g} \mathrm{Kg}^{-1}$ in the lower $250 \mathrm{~m}$ layer is noticed in the observations and no such variation is noticed in the simulations (figure 4(d)). Nearly constant specific humidity layer of the thickness $\sim 850 \mathrm{~m}$ from the surface is seen in the observations (figure 4(c)). A maximum difference of $\sim 3 \mathrm{~g} \mathrm{Kg}^{-1}$ (figure 4(c)) and $\sim 4 \mathrm{~g} \mathrm{Kg}^{-1}$ (figure 4(d)) in the lower layers of the atmosphere is found between simulations and observations. In contrast, there is an initial decrease of specific humidity of $\sim 5 \mathrm{~g} \mathrm{Kg}^{-1}$ (figure $5(\mathrm{c})$ ) and $\sim 4 \mathrm{~g} \mathrm{Kg}^{-1}$ (figure $5(\mathrm{~d})$ ) is noticed in the lower $250 \mathrm{~m}$ layer.

There are limitations of one-dimensional model to simulate the boundary layer processes due to nonhomogeneity and advection. On overall evaluation of the results, the model could be able to simulate MBL processes reasonably well.

Figures 6 and 7 represent the diurnal variation of fluxes of sensible heat and latent heat, MBL height and drag coefficient for Case- 1 and Case-2, respectively. The diurnal variation of these parameters is 

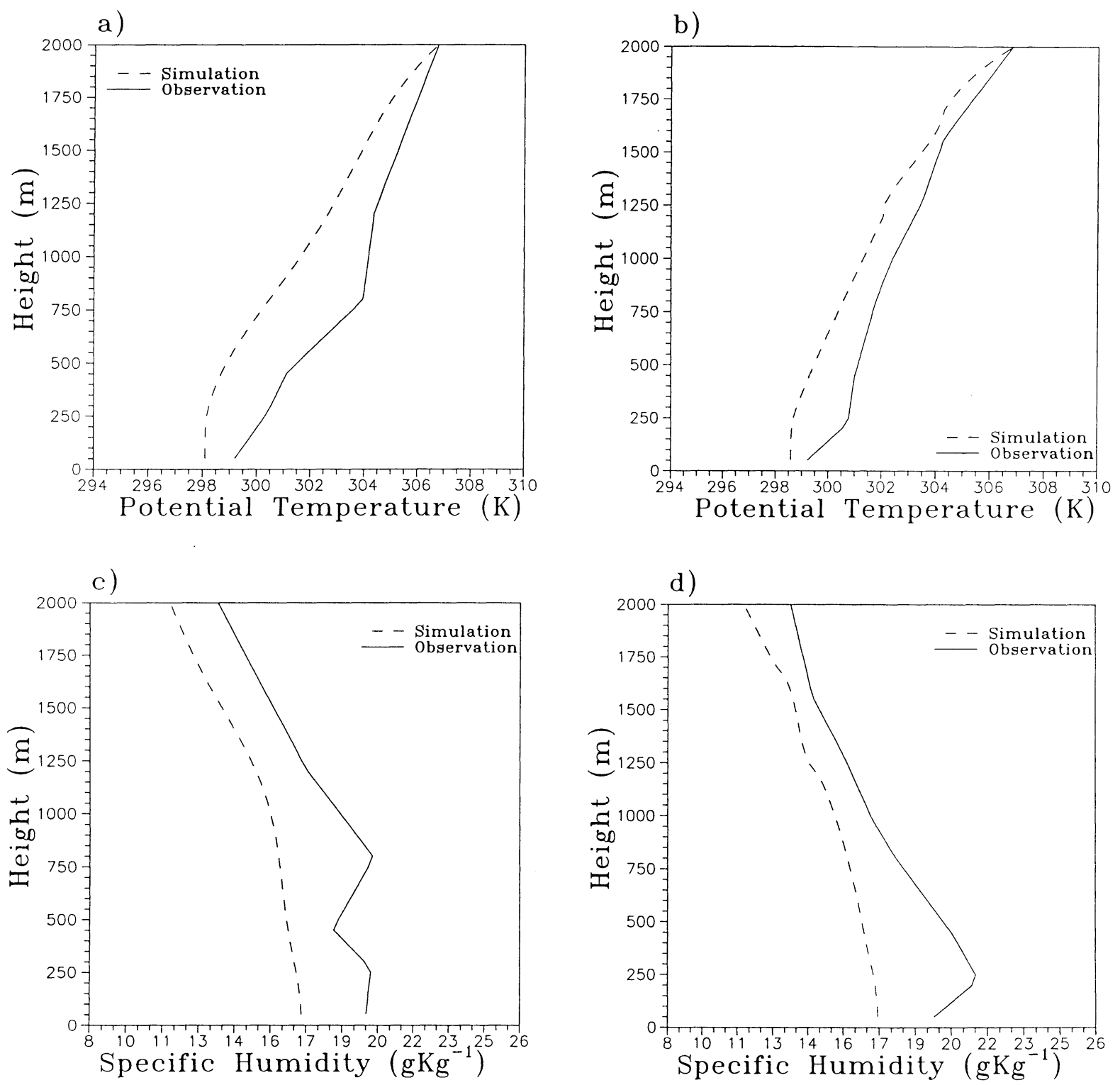

Figure 4. Vertical profiles of (a) potential temperature (K) at 00 UTC on 1st November 1998; (b) same as (a) but at 00 UTC on 2nd November 1998; (c) specific humidity $\left(\mathrm{g} \mathrm{Kg}^{-1}\right)$ at 00 UTC on 1st November 1998 and; (d) same as (c) but at 00 UTC on 2nd November 1998 along with the observations of Case-1.

plotted with respect to UTC timings on the abscissa. For example, for Case-1, 0 hours can be read as 0530 IST of 31st October 1998, 24 hours as 0530 IST of 1st November 1998 and 48 hours as 0530 IST of 2nd November 1998. Similarly for Case-2, 0 hours can be read as 0530 IST of 3rd November 1998, 24 hours as 0530 IST of 4 th November 1998 and 48 hours as 0530 IST of 5th November 1998.

In Case-1, the model simulated sensible heat and latent heat fluxes values are higher than in Case-2. A maximum sensible heat flux value of $47.7 \mathrm{Wm}^{-2}$ is noticed in Case-1 (figure $6(\mathrm{a})$ ) while $13.8 \mathrm{Wm}^{-2}$ in Case-2 (figure $7(\mathrm{a})$ ) in the model simulations. Similarly, a maximum magnitude of simulated latent heat flux of $414 \mathrm{Wm}^{-2}$ is seen in figure $6(\mathrm{~b})$ while $190 \mathrm{Wm}^{-2}$ in figure $7(\mathrm{~b})$. The observed fluxes of sensible heat and latent heat are overlaid on the simulation curve in figures $6(\mathrm{a}), 7(\mathrm{a}), 6(\mathrm{~b})$ and $7(\mathrm{~b})$. A maximum observed sensible heat flux of $\sim 33 \mathrm{Wm}^{-2}$ is noticed in Case-1 while $\sim 15 \mathrm{Wm}^{-2}$ in Case-2. A higher observed latent heat flux of $196 \mathrm{Wm}^{-2}$ is seen in Case- 1 where as $176 \mathrm{Wm}^{-2}$ in Case-2. But for most of the time the values of latent heat flux in Case- 1 are on a higher range when compared with the values of Case-2. The under-estimation of simulated fluxes of sensible heat and latent heat with respect to the observations can be probably due to the extracted and vertically interpolated and hence smooth wind profiles that are used in the model as obtained from the coarse resolution NCMRWF analyses. Due to the nonavailability of sufficient observations of these fluxes during this study period, it is rather difficult to 
a)

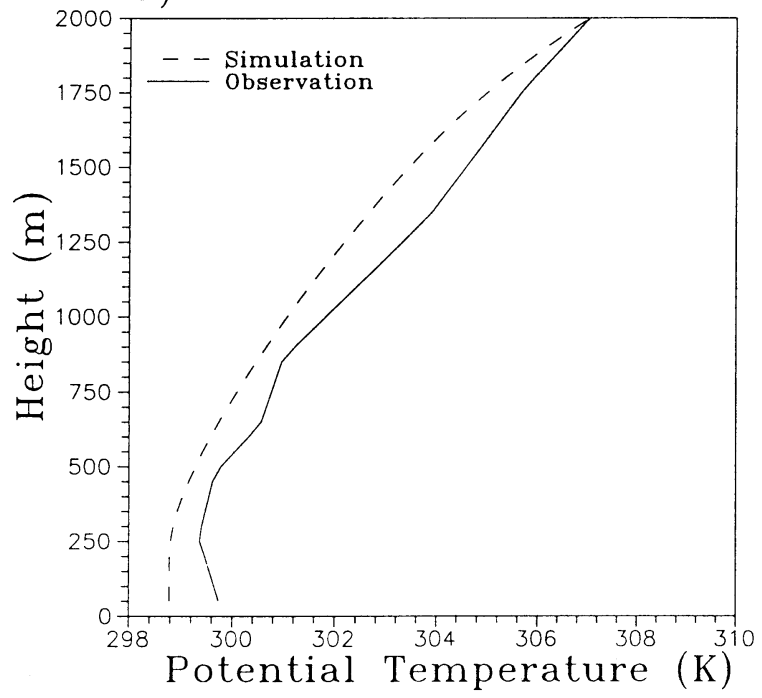

c)

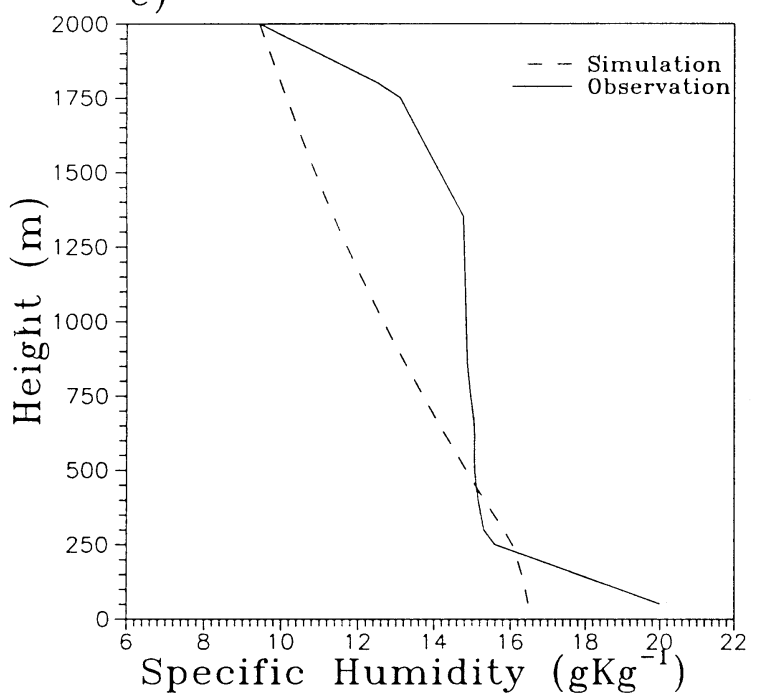

b)

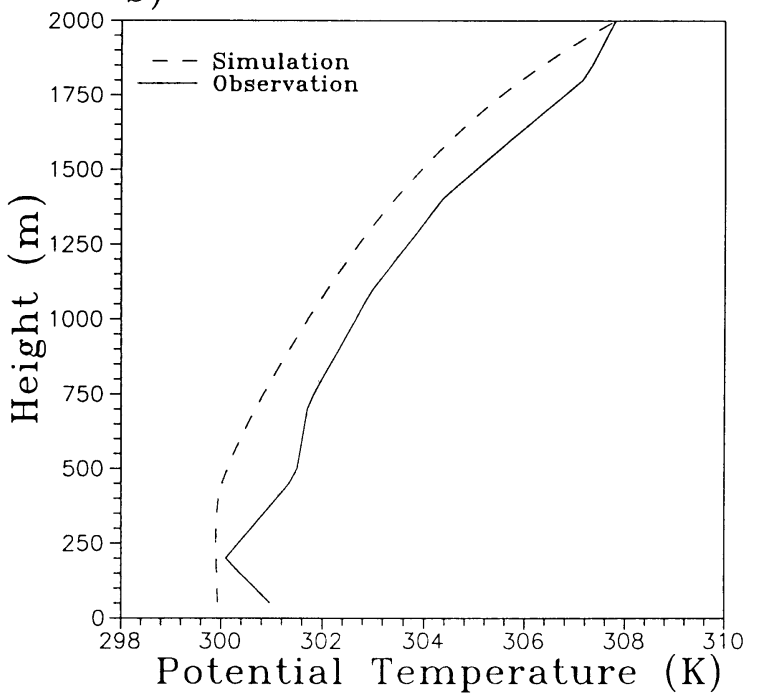

d)

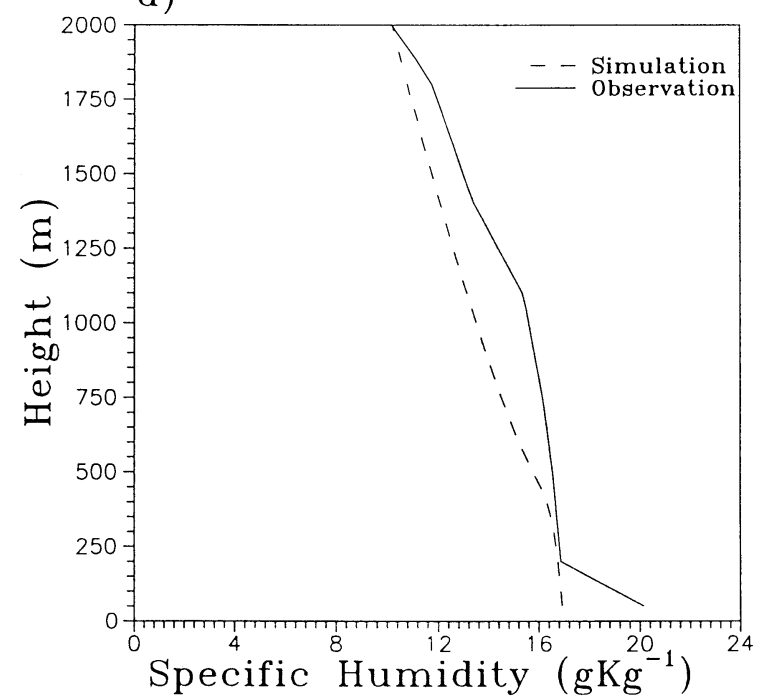

Figure 5. Vertical profiles of (a) potential temperature (K) at 00 UTC on 4th November 1998; (b) same as (a) but at 00 UTC on 5 th November 1998; (c) specific humidity $\left(\mathrm{g} \mathrm{Kg}^{-1}\right)$ at 00 UTC on 4th November 1998 and; (d) same as (c) but at 00 UTC on 5th November 1998 along with the observations of Case-2.

compare with the simulated diurnal variation. But on comparing the magnitudes of the fluxes of sensible and latent heat, one can see, as cited above, higher values in Case- 1 than in Case-2. The reason could be due to the overcast conditions that are prevalent in Case-1.This may lead to thorough mixing due to both mechanical and buoyancy generated turbulence which results in more vertical transportation of the energy for the ocean surface into the boundary layer. In such a scenario, more loss of energy in the form of sensible heat flux, latent heat flux (incoming solar radiation cutoff due to overcast conditions) from the ocean leads to net-oceanic loss (Mohanty and Mohan Kumar 1990). In this process, there may be a regular supply of heat and moisture from the ocean surface into the atmosphere above for the maintenance of deep convection and cyclogenesis leading to depression.

From the simulations, a maximum MBL height of $\sim 640 \mathrm{~m}$ above is found during Case-1 (figure 6(c)) while a maximum of $400 \mathrm{~m}$ is noticed during Case-2 (figure 7(c)). The estimated MBL height values from the available observations are also plotted against the simulations. The overall variation of the model simulations of MBL height and the observations are fairly in good agreement. This could be attributed to the fact that the more the vertical transportation sensible heat flux, the more the height of the boundary layer height.

No specific variation of the drag coefficient is noticed in the model simulations in both Case-1 (figure 6(d)) 

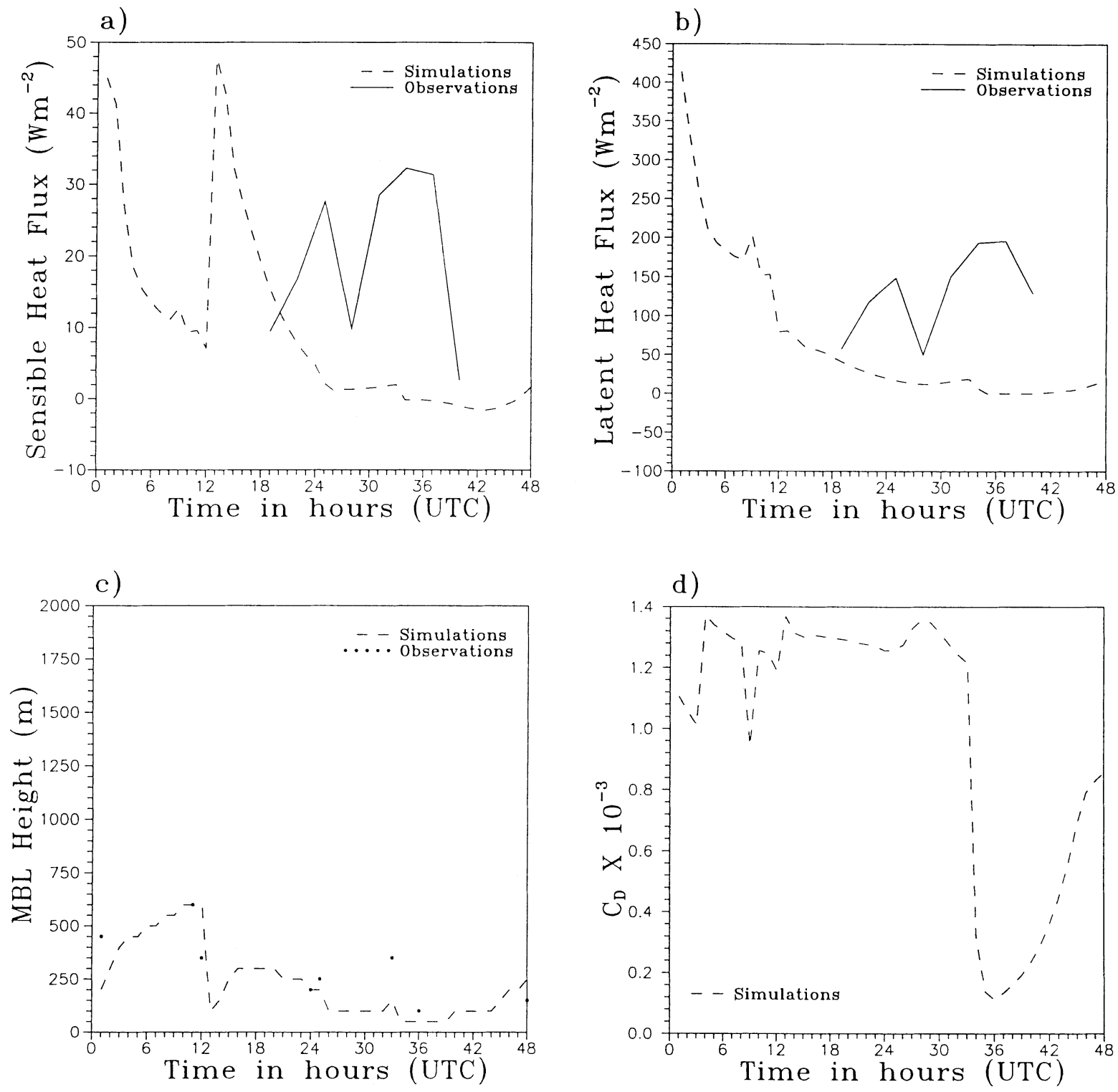

Figure 6. Diurnal variation of (a) sensible heat flux $\left(\mathrm{Wm}^{-2}\right)$; and; (d) drag coefficient $\left(\mathrm{ms}^{-2}\right)$ of Case-1.

and Case-2 (figure 7(d)). Most of the time the drag coefficient in Case-1 is higher than in Case-2. A maximum value of $1.37 \times 10^{-3}$ is noticed in Case- 1 while a higher magnitude of $1.29 \times 10^{-3}$ is found in Case-2. The higher values in Case-1 might be due to relatively higher winds since drag coefficient is a function of horizontal wind speed. The magnitude of the drag coefficient is well within the limits as noticed elsewhere (Stull 1988).

From the simulations of temporal variation of TKE, it is noticed that the TKE generation is more with a maximum magnitude of $0.34 \mathrm{~m}^{2} \mathrm{~s}^{-2}$ in Case-1 (figure 8(a) where as it is less in Case-2 (figure 8(b)). It may be due to relatively strong winds in Case- 1 and more generation of sensible heat flux. In Case-2, TKE generation is less and a magnitude of $0.18 \mathrm{~m}^{2} \mathrm{~s}^{-2}$ is noticed. The extent of TKE in vertical defines the
MBL height. On comparing temporal variation of TKE with MBL height, one can see the synonymous variation.

RMS error and correlation coefficient are computed to evaluate the performance of the model simulations with respect to the observations for both Case- 1 and Case- 2 and shown in table 1. A maximum RMS error of $1.71 \mathrm{~K}$ is noticed in potential temperature profiles (Case-1) whereas in the case of specific humidity (Case-1) a maximum error of $2.36 \mathrm{~g} \mathrm{Kg}^{-1}$ is seen. In Case-2, a higher RMS error of $1.16 \mathrm{~K}$ is seen in potential temperature profiles, whereas it is $1.89 \mathrm{~g} \mathrm{Kg}^{-1}$ in specific humidity profiles. In both the cases the simulated profiles of potential temperature and specific humidity are fairly correlated with the observations, whereas zonal and meridional profiles are reasonably correlated. 


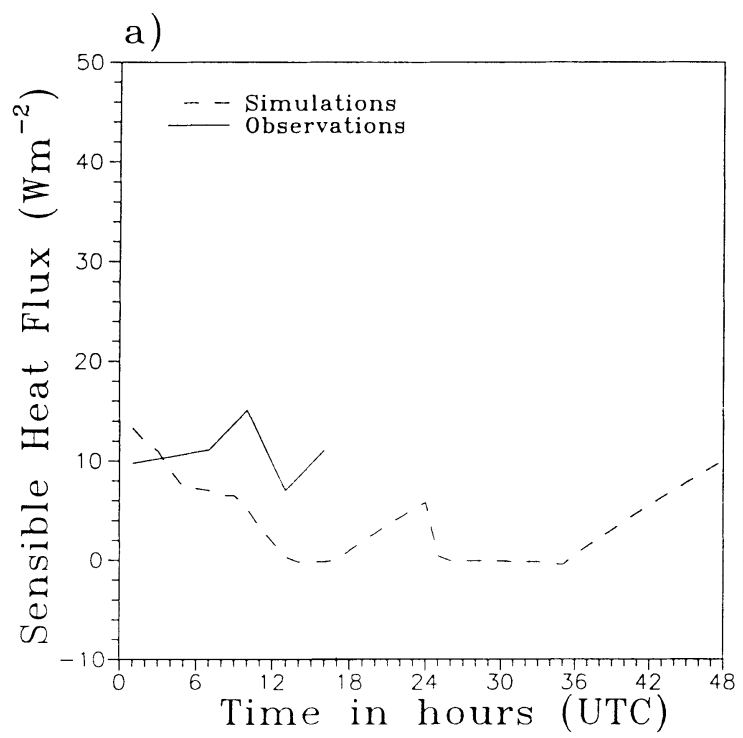

b)

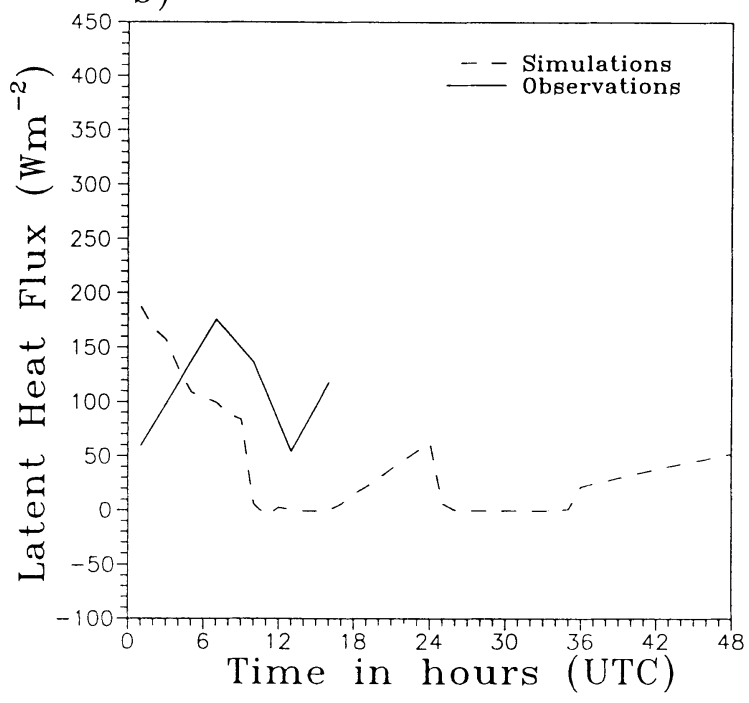

c)
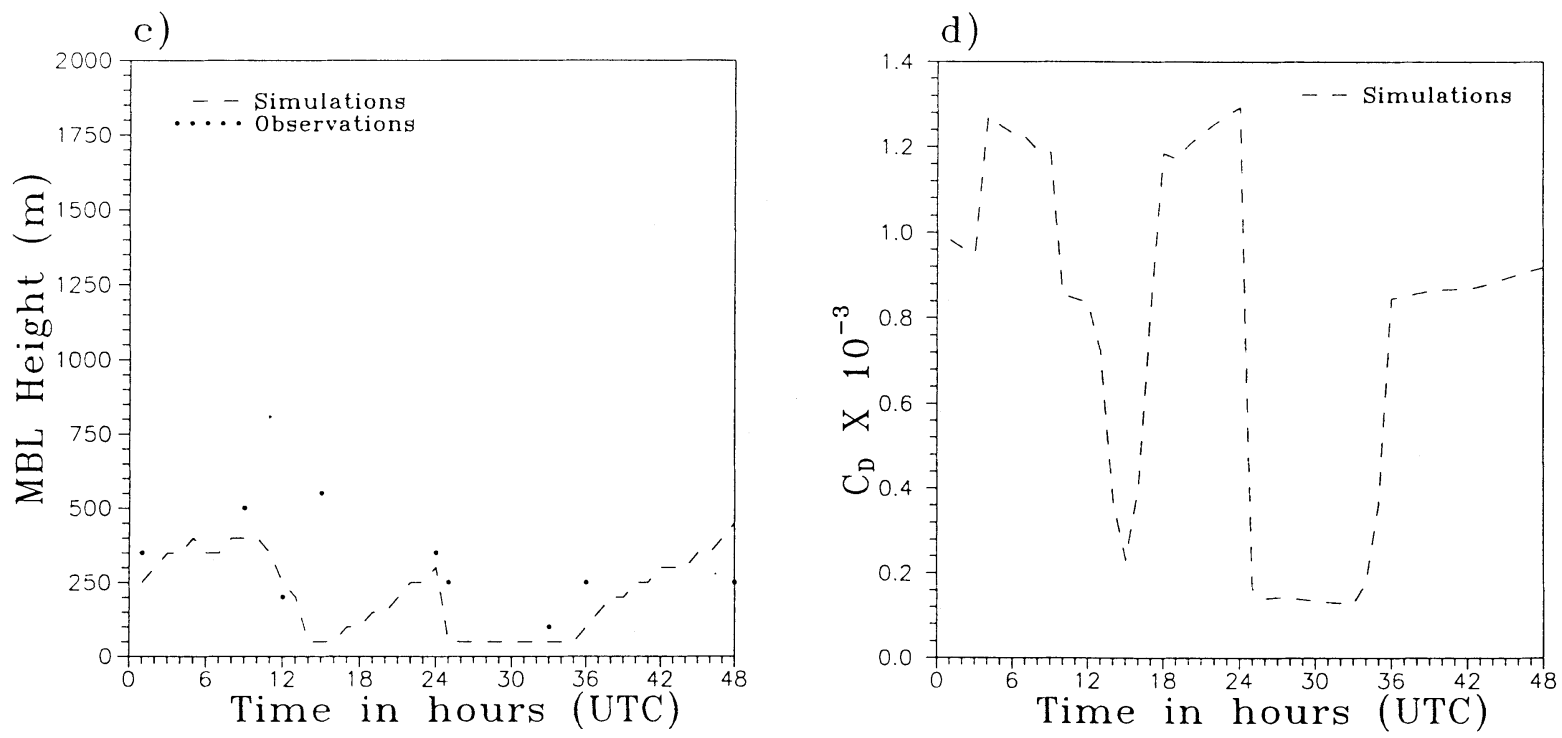

Figure 7. Diurnal variation of (a) sensible heat flux $\left(\mathrm{Wm}^{-2}\right)$; (b) latent heat flux $\left(\mathrm{Wm}^{-2}\right)$; (c) marine boundary layer height (m) and; (d) drag coefficient $\left(\mathrm{ms}^{-2}\right)$ of Case-2.

\section{Conclusions}

A multi-level one-dimensional boundary layer model was successfully employed to simulate marine boundary layer processes over the Bay of Bengal during BOBMEX-98 pilot campaign. The MBL characteristics were simulated for two distinctly different observational scenarios: one during active convection and the other during suppressed convection. The model was able to capture the main characteristic features of these two synoptic situations.

From the results of the numerical simulations carried out in this study, the following broad conclusions are drawn.

The model simulations of vertical profiles of potential temperature and specific humidity are found to be in fair agreement with the observations. The model simulation of zonal and meridional wind components does show some deviations with the observations due to the limitations of the one-dimensional model. In general the model could capture the thermodynamic and dynamical fields reasonably well.

The model was able to simulate fairly well the temporal variation of fluxes of sensible heat and latent heat when compared with the observations to bring out the different transportation in different synoptic scenarios. Higher fluxes of sensible heat and latent heat are noticed in the active convection case than that in clear weather situation. The simulated MBL in the active convection case is higher than in the suppressed convection case. The simulated MBL height is in good agreement with the estimated values. The 
a)

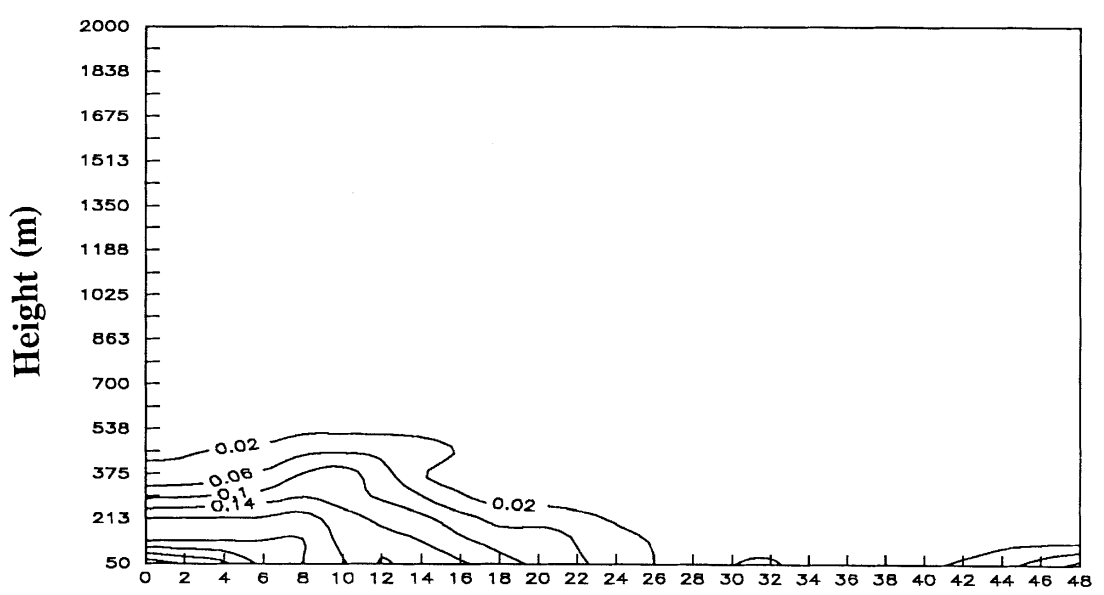

b)

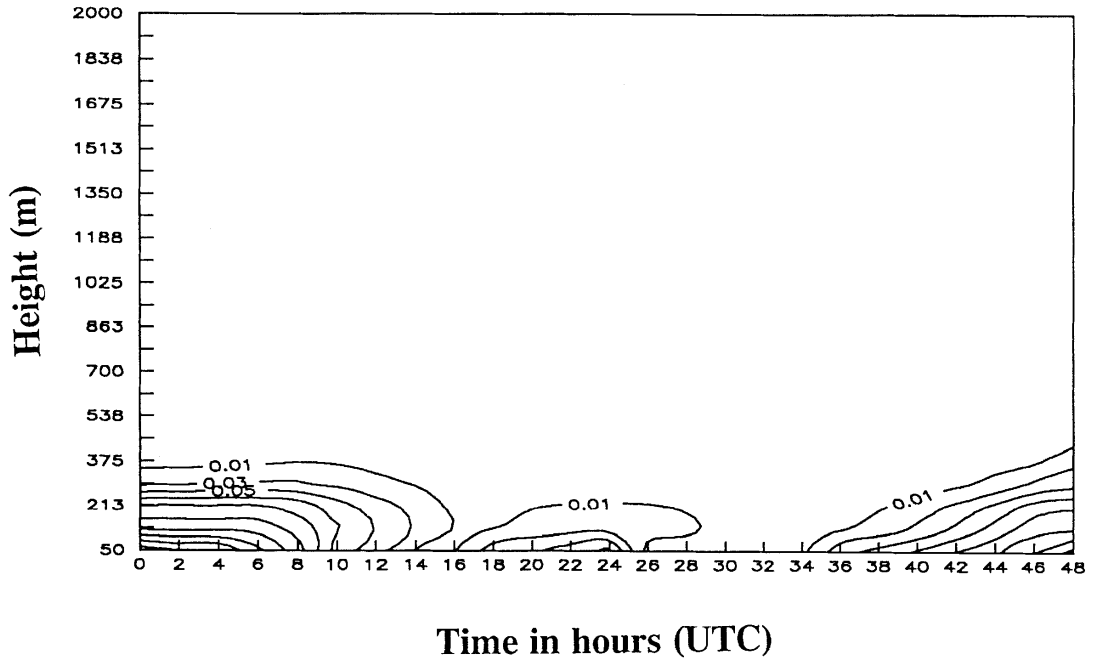

Figure 8. Time evolution of turbulent kinetic energy $\left(\mathrm{m}^{2} \mathrm{~s}^{-2}\right)$ of (a) Case-1 and (b) Case-2.

Table 1. Statistical evaluation of the performance of the model in the simulation of zonal wind $\left(\mathrm{ms}^{-1}\right)$, meridional wind $\left(\mathrm{ms}^{-1}\right)$, potential temperature $(\mathrm{K})$ and specific humidity $\left(\mathrm{g} \mathrm{Kg}^{-1}\right)$.

\begin{tabular}{|c|c|c|c|c|c|}
\hline \multirow{2}{*}{$\begin{array}{l}\text { Simulation } \\
\text { hours for } \\
\text { Case-1/Case-2 }\end{array}$} & \multirow[b]{2}{*}{ Parameter } & \multicolumn{2}{|c|}{ Case-1 } & \multicolumn{2}{|c|}{ Case-2 } \\
\hline & & RMS error & Corr. coeff. & RMS error & Corr. coeff. \\
\hline \multirow[t]{4}{*}{$12 / 12$} & $\mathrm{U}$ & 0.69 & 0.85 & 0.59 & 0.90 \\
\hline & $\mathrm{V}$ & 0.82 & 0.30 & 0.65 & 0.77 \\
\hline & $\theta$ & 1.64 & 0.95 & 0.00 & 0.99 \\
\hline & $q$ & 2.12 & 0.91 & 0.52 & 0.95 \\
\hline \multirow[t]{4}{*}{$24 / 24$} & $\mathrm{U}$ & 0.32 & 0.94 & 0.00 & 0.98 \\
\hline & $\mathrm{V}$ & 1.41 & 0.95 & 0.82 & -0.89 \\
\hline & $\theta$ & 1.71 & 0.96 & 0.47 & 0.99 \\
\hline & q & 2.20 & 0.98 & 1.89 & 0.82 \\
\hline \multirow[t]{4}{*}{$36 / 36$} & $\mathrm{U}$ & 0.82 & 0.78 & 0.35 & 0.99 \\
\hline & $\mathrm{V}$ & 0.59 & 0.62 & 0.00 & 0.81 \\
\hline & $\theta$ & 0.27 & 0.98 & 1.16 & 0.98 \\
\hline & $q$ & 2.36 & 0.91 & 1.00 & 0.99 \\
\hline \multirow[t]{4}{*}{$48 / 48$} & $\mathrm{U}$ & 0.67 & 0.72 & 0.89 & 0.22 \\
\hline & $\mathrm{V}$ & 0.00 & 0.99 & 0.00 & 0.92 \\
\hline & $\theta$ & 0.91 & 0.99 & 0.65 & 0.99 \\
\hline & $q$ & 1.94 & 0.96 & 1.15 & 0.95 \\
\hline
\end{tabular}


model simulated drag coefficient values in the present study compare reasonably with the values quoted in the literature. The TKE evolution does not show any specific temporal variation. But in the active convection case TKE is found to be higher. On the statistical evaluation of the simulations, it is noticed that the RMS error and correlation coefficient are fairly reasonable in the case of vertical profiles of potential temperature and specific humidity whereas they are reasonable in the case of zonal and meridional wind profiles.

\section{Acknowledgements}

We would like to express our gratitude to the scientific team of ORV Sagar Kanya for their participation in the BOBMEX-98 pilot experiment cruise for the collection of the atmospheric data set. We gratefully thank Department of Science and Technology (DST) for sponsoring the experiment. The authors would like to express their thanks to Dr. G S Bhat, Centre for Atmospheric and Oceanic Sciences, Indian Institute of Science for providing few data sets for this study. We also owe our thanks to Dr R K Paliwal, NCMRWF for his interest in the study.

\section{References}

Holt T and Raman S 1988 Rev. Geophys. 264 761-780.

Kalsi S R Workshop on Bay of Bengal and Monsoon Experiment (BOBMEX) Pilot Study Results, 19 April 1999, IIT Delhi, India

Lykossov V N and Platov G A 1992 Russ. J. Numer. Anal. Math. Modelling 7 419-440.

Mellor G L and Yamada T 1974 J. Atmos. Sci. 31, 1791-1806.

Mohanty U C and Mohan Kumar 1990 Atmospheric Environment, 24A, 823-828

Satyanarayana A N V, Mohanty U C and Sam N V 1999 Curr. Sci. 76 890-897.

Stull R 1988 An Introduction to Planetary Boundary Layer, (Dordrecht, The Netherlands: Kluwer Academic Publishers) $666 \mathrm{pp}$ 